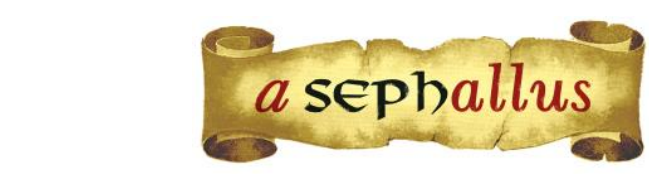

Revista aSEPHallus de Orientação Lacaniana

Núcleo Sephora de Pesquisa sobre o Moderno e o Contemporâneo

ISSN $1809-709$ X

\title{
0 método analítico e as psicoses: do dispositivo freudiano à estrutura lacaniana
}

\author{
Andréa Martello \\ Professora do Programa de Pós-Graduação em Teoria Psicanalítica da Universidade Federal do Rio de Janeiro \\ PPGTP/UFRJ - (Rio de Janeiro, Brasil) \\ Professora da Escola de Educação da Universidade Federal do Estado do Rio de Janeiro \\ UNIRIO (Rio de Janeiro, Brasil) \\ E-mail: deamartello@gmail.com
}

Eveline Andries de Castro Professora das Faculdades Integradas Pitágoras de Montes Claros FIPMOC (Montes Claros, Brasil) Mestre pelo Programa de Pós-Graduação em Teoria Psicanalítica da Universidade Federal do Rio de Janeiro PPGTP/UFRJ (Rio de Janeiro, Brasil) Psicóloga da Prefeitura Municipal de Montes Claros (Montes Claros, Brasil) E-mail: eveacastro@yahoo.com.br

Renata Rosa da Costa
Especialista em Psicologia Clínico-Institucional pela Universidade do Estado do Rio de Janeiro UERJ (Rio de Janeiro, Brasil) Mestranda do Programa de Pós-graduação em Teoria Psicanalítica da Universidade Federal do Rio de Janeiro PPGTP/UFRJ (Rio de Janeiro, Brasil) Psicóloga pela Universidade Federal do Rio de Janeiro UFRJ (Rio de Janeiro, Brasil) E-mail: renatarosa.psi@gmail.com

\section{RESUMO}

O artigo retoma as formulações teóricas de Freud acerca da diferença entre os campos da neurose e da psicose e dos limites do tratamento psicanalítico com psicóticos para, em seguida, apresentar as contribuições de Jacques Lacan à temática da psicose, no que alude à sua diferença estrutural, seu mecanismo específico e direção do tratamento. Demarca-se com o recorte teórico, uma revisão bibliográfica sobre o período a partir do qual Freud deixa de conceber a psicose pelo paradigma da neurose e em que o retorno efetivado por Lacan a Freud, com base em suas apropriações da linguística e da antropologia estrutural, deu centralidade à determinação do sujeito pela linguagem, à valorização do simbólico; permitindo com isso novas possibilidades para o tratamento da psicose.

Palavras-Chave: método analítico, neurose, psicose, linguagem.

\begin{abstract}
EL MÉTOdO ANALÍTICO Y LAS PSICOSIS: DEL DISPOSITIVO FREUDIANO A LA ESTRUCTURA LACANIANA: El artículo retoma las formulaciones teóricas de Freud acerca de la diferencia entre los campos de la neurosis y de la psicosis y de los límites del tratamiento psicoanalítico con psicóticos para en seguida, presentar las contribuciones de Jacques Lacan a la temática de la psicosis, lo que se refiere a la diferencia estructural, al mecanismo específico y a la dirección del tratamiento. Se demarca con el recorte teórico, una revisión bibliográfica sobre el período a partir del cual Freud deja de concebir la psicosis por el paradigma de la neurosis y en que el retorno hecho efectivo por Lacan a Freud, con base en sus apropiaciones de la lingüística y de la antropología estructural, le da la centralidad a la determinación del sujeto por el lenguaje a la valorización de lo simbólico, permitiendo con ello, nuevas posibilidades para el tratamiento de la psicosis.

Palabras Clave: método analítico, neurosis, psicosis, lenguaje.
\end{abstract}

THE ANALYTICAL METHOD AND THE PSYCHOSES: FROM THE FREUDIAN DEVICE TO THE LACANIAN STRUCTURE: This article takes up Freud's theoretical formulations about the difference between the neurosis and psychosis fields and the psychoanalytical limitations treatment with psychotic to, then, submit the Jacques Lacan's contributions to the psychosis theme, as referred to their structural differences, their specific mechanism and treatment direction. It is delimited with the theoretical framework, a review on the period from which Freud fails to conceive the psychosis by the neurosis paradigm and the return effected by Lacan to Freud, based on their appropriation of linguistics and anthropology structural, gave centrality to the subject determination by the language, the symbolic appreciation; thereby providing new possibilities for the psychosis treatment.

Keywords: analytical method, neurosis, psychosis, language. 


\section{0 método analítico e as psicoses: do dispositivo freudiano à estrutura lacaniana}

Andréa Martello, Eveline Andries de Castro \& Renata Rosa da Costa

\section{Ponto de partida freudiano: as neuroses}

Paralisias, convulsões, cegueira, surdez: teoria e clínica psicanalíticas surgiram do encontro entre Sigmund Freud e pacientes cujas sintomatologias físicas não apresentavam causa orgânica. Deste encontro originou-se um método revolucionário no âmbito terapêutico que promove a escuta do paciente visando investigar o sentido de seus sintomas. Ao trabalho de escuta soma-se o da interpretação baseada na teoria do inconsciente que fornece inteligibilidade aos sintomas, revelando um sentido oculto e geralmente particular. O conjunto de saberes adquiridos através da aplicação deste método deu ao inventor da psicanálise as chaves para a compreensão e aprimoramento das regras do inconsciente. Ao dar lugar à escuta da fantasia e da realidade psíquica e ao considerar de modo decisivo o papel da transferência no tratamento analítico, Freud consolidou uma perspectiva terapêutica para a neurose. Não por acaso, pois, tratou-se de um desafio desenvolver a compreensão psicanalítica das psicoses.

Foi debruçando-se sobre a neurose que Freud chegou à hipótese da sexualidade infantil, do complexo de Édipo e do mecanismo do recalque, pressupostos fundamentais ao método psicanalítico. No início de suas formulações teóricas, baseado na escuta de pacientes histéricos, Freud concluiu que as experiências desencadeadoras dos sintomas remontavam aos primeiros anos de vida. $O$ autor defendia que em tais pacientes operava o retorno de uma lembrança da infância, de caráter traumático e sexual. No entanto, face à multiplicidade de relatos semelhantes, e tendo observado indícios da existência da sexualidade infantil a partir de sua autoanálise, passou a considerar a fantasia inerente aos relatos de cenas traumáticas, renunciando, desse modo, à teoria da sedução (Freud, 1897/2006).

Freud passa a entender a etiologia do trauma como fantasmática, mais do que real. 0 complexo de Édipo foi articulado neste contexto, aludindo à tragédia e mitologia grega, na qual Édipo rei mata o pai e desposa a mãe, e apontando assim, para a existência de um impulso incestuoso infantil e todas as fantasias dele decorrentes (Freud, 1905a/2006). Aqui Freud passou a encarar o sintoma neurótico como resultado de um processo defensivo inconsciente - o recalque. Este atuaria contra uma representação cujo conteúdo a consciência não tolera. Tal ideia o levou à suposição da existência do inconsciente, instância psíquica onde residiriam lembranças esquecidas, rechaçadas, inibidas e suprimidas (Freud, 1893/2006).

Para a teoria freudiana, aquele que não se liberta da atração incestuosa, nem mesmo com o auxílio da figura paterna, está fadado à neurose. Nesses casos, a tentação do incesto manter-seia em pensamentos inconscientes e a barreira seria transgredida nas fantasias, as quais dariam notícias através do conteúdo dos sonhos e dos sintomas (Freud, 1905b/1990). 
Na neurose haveria, pois, uma introversão da libido, a qual toma a via da regressão reanimando imagens infantis. Ou seja, a libido nestes casos é retida no curso do desenvolvimento, mantendo-se afastada da consciência e da realidade. E, ao dispositivo analítico, caberia segui-la e encontrá-la, tornando-a assim novamente acessível à consciência, pondo-a à serviço da realidade (Freud, 1912a/ 2006, p. 139). Freud, no entanto, observou que as forças que causaram a introversão e a regressão da libido atuam no sentido de conservar este estado de coisas, levantando-se como resistência ao tratamento. Este, por sua vez, teria como direção a superação e eliminação da resistência a qual será identificada por meio do monitoramento da transferência.

Não se discute que controlar os fenômenos da transferência representa para o psicanalista as maiores dificuldades; mas não se deve esquecer que são precisamente eles que nos prestam o inestimável serviço de tornar imediatos e manifestos os impulsos eróticos ocultos e esquecidos do paciente. (Freud, 1912a/ 2006, p. 65)

Veremos que Freud não via cumprir sua expectativa de "vencer as resistências, remover a repressão e transformar o material inconsciente em material consciente" (Freud, 1917b/ 2006, p. 129) em suas tentativas de analisar psicóticos. Desse modo, afirmava que a psicose era imprópria à psicanálise (Freud, 1905c/ 2006, p. 163), sendo ela uma condição incurável (1913c/2006, p. 121).

A incapacidade de realizar a transferência no processo de análise foi apontada como um fator decisivo para a impossibilidade de tratamento nestes casos, já que a elaboração das resistências é considerada a principal forma de descobrir os impulsos instintuais e promover um efeito modificador no paciente (Freud, 1914a/2006). Tal incapacidade será aqui discutida posteriormente.

\section{Diferença entre neurose e psicose e as limitações do tratamento analítico}

Freud $(1911 a / 2006 ; 1924 / 2006)$ propôs que o adoecimento psíquico está estreitamente ligado a um afastamento da realidade por parte do doente, uma vez que este a consideraria, no todo ou em parte, insuportável. A seu ver, haveria na psicose, diferentemente da neurose, um tipo mais extremo de afastamento da realidade, onde a libido desprendida voltar-se-ia para o eu gerando um represamento e consequente fixação narcísica (Freud, 1911a/2006):

Um paciente que sofre de histeria ou de neurose obsessiva, enquanto sua doença persiste, também desiste de sua relação com a realidade. Mas a análise demonstra que ele de modo algum corta suas relações eróticas com as pessoas e as coisas. Ainda as retém na fantasia. [...] Com o parafrênico [psicótico] a situação é 
diferente. Ele parece realmente ter retirado sua libido de pessoas e coisas do mundo externo, sem substituí-las por outras na fantasia. Quando realmente as substitui, o processo parece ser secundário e constituir parte de uma tentativa de recuperação, destinada a conduzir a libido de volta a objetos (Freud, 1914c/2006, p. 46).

Em 1894, em seu artigo "Neuropsicoses de defesa", também destacava na psicose uma espécie de defesa mais poderosa e bem-sucedida do que na neurose, nomeando como Verwerfung o mecanismo que rejeita a representação e o afeto intoleráveis para o sujeito. Todavia, como Coelho dos Santos e Oliveira (2012, p. 74) observam: "embora o termo Verwerfung [rejeição] já aparecesse nas elaborações freudianas acerca da psicose no artigo de 1894, não tinha ainda a densidade conceitual que passaria adquirir posteriormente".

A diferença determinante entre os quadros de neurose e psicose foi formalizada apenas nos artigos de 1924, elaborados após os desdobramentos da teoria do narcisismo nas formulações da segunda tópica do funcionamento mental (Freud, 1923/2006). A partir daí, verifica-se que o paradigma do recalque (Verdrängung) e suas modalidades de defesa são finalmente abandonados pelo autor como modelo elucidativo dos fenômenos psicóticos (Coelho dos Santos \& Oliveira, 2012, p. 77).

\section{Schreber e o delírio do fim de mundo}

$\mathrm{Na}$ análise do caso Schreber, Freud (1911a/2006) entendeu que os paranoicos revelam, ainda que de forma distorcida, conteúdos que os neuróticos escondem como uma espécie de segredo, isto é, as alucinações e os delírios expõem o conteúdo que, na neurose, o sonho e o sintoma buscam encobrir. Desta forma, conseguiu identificar o complexo paterno nas construções de Schreber. O conflito com Deus foi traduzido como um conflito com o pai e a ameaça de castração proporcionou a fantasia de transformação em mulher.

Como os casos de psicose remetem a um tipo mais extremo de afastamento da realidade, o psicótico é aquele que retirou do mundo externo todo seu investimento libidinal e, devido a isso, trata as pessoas e o ambiente ao seu redor com indiferença. Esse desinteresse pelo mundo externo traduziu-se, no caso de Schreber, em seu delírio de fim de mundo, posto que todos os raios divinos eram atraídos para si próprio - permitindo a Freud (1911a/2006, p. 43) afirmar que "o fim do mundo é a projeção dessa catástrofe interna; seu mundo subjetivo chegou ao fim, desde o retraimento de seu amor por ele".

É possível notar que tanto delírios quanto alucinações são relacionados pelas considerações freudianas a um serviço de remodelamento, ou seja, a um esforço feito pelo fragmento da realidade rejeitado de se impor ao psiquismo daquele que o rejeitou. Não obstante, 
tal fragmento depara-se com forças opositoras as quais dão aos fenômenos presentes na psicose um caráter aflitivo (Freud, 1924b/2006).

Em 1914, no artigo intitulado "Sobre o narcisismo: uma introdução", Freud reafirmou a ideia do delírio como tentativa de restauração de uma perda de realidade que caracteriza, por si só, a doença. Desta forma, duas características fundamentais da psicose destacam-se: o abandono do interesse pelo mundo externo e a megalomania. De acordo com sua tese, os psicóticos, furtamse à influência da psicanálise devido à retirada de investimento no mundo externo (Freud, 1914c/2006, p. 45-46), de modo que, na psicose não se alimenta essa relação com o mundo externo através da fantasia inconsciente.

\section{Ideal do eu: operador transferencial em questão no caso das psicoses}

A psicanálise freudiana encontra uma forma de explicar os fenômenos observados em seus pacientes e atribuiu à hipocondria e à psicose um represamento da libido do eu em detrimento da libido de objeto, que é sentido como desprazeroso em virtude da alta tensão proporcionada (Freud, 1914c/2006). E, a partir dos elementos presentes no quadro clínico da psicose, foi possível mapear uma conduta narcísica causada pelo represamento libidinal. Assim, na neurose, a relação erótica com pessoas e coisas é mantida na fantasia através dos protótipos infantis e se atualiza na repetição através da transferência. Já, na psicose, há a suspensão dessas relações, produzindo, como resultado, o desenvolvimento da megalomania ou hipocondria, que trazem a marca do narcisismo na constituição do eu (Freud, 1914c/2006). É neste sentido que se discute a incapacidade do psicótico realizar a transferência tal como era prevista por Freud.

Através do problema da psicose e de sua inacessibilidade narcísica, foi possível inferir e reconhecer que, em determinado momento, posterior ao autoerotismo, a criança encontra-se inflada deste narcisismo - que se relaciona com a constituição do ego e cuja peculiaridade nas psicoses é indicativa de um fracasso desta operação em seu momento adequado. Entretanto, o narcisismo normal sofre, ao longo do desenvolvimento, feridas e perturbações, fazendo com que a perfeição da infância deva ser renunciada. Em paralelo, o indivíduo pouco a pouco, passa a reconhecer valores morais e culturais como determinantes para si e elege um ideal para o qual é deslocado o narcisismo infantil (Freud, 1914c/2006):

Esse ego ideal é agora o alvo do amor de si mesmo (self-love) desfrutado na infância pelo ego real. $\mathrm{O}$ narcisismo do indivíduo surge deslocado em direção a esse novo ego ideal, o qual, como o ego infantil, se acha possuído de toda perfeição de valor. [...] 0 que ele projeta diante de si como sendo seu ideal é o substituto do narcisismo perdido de sua infância na qual ele era o seu próprio ideal. (Freud, 1914c/2006, p. 57-58) 
Nesse sentido, a satisfação narcísica será alcançada a partir do ideal do eu e para isso, exige-se do eu (ego ideal) que ele esteja à altura das exigências do ideal. A consciência moral aparece como uma instância cujo propósito é realizar esta exigência e sua instituição trata-se da corporificação da crítica dos pais, educadores e da sociedade de modo geral (Freud, 1914c/2006). Segundo Freud, o delírio de ser perseguido apresenta esta instância de forma regressiva. Desse modo, por ter se revoltado contra a mesma e todas suas influências, a começar pela dos pais, o indivíduo psicótico retiraria sua libido destas críticas, as quais apareceriam como hostis interferências externas (Freud, 1914c/2006).

Já em 1895, no "Rascunho H", Freud apontava a projeção como mecanismo próprio da paranoia. Nestes casos, ao defender-se de um conteúdo insuportável, o indivíduo projeta-o no mundo exterior, ou seja, a autocensura, típica deste quadro clínico, é deslocada transformando-se em uma recriminação externa. Ao empreender essa manobra, o indivíduo permite-se rejeitar o que Ihe chega, isto é, passa a rejeitar a censura que, outrora, era parte de si (Freud, 1895/2006). Na psicose, não há um deslocamento do narcisismo infantil para o ideal do eu, pelo contrário, a libido é retirada de toda e qualquer uma de suas influências. Desta forma, o ideal do eu não é internalizado e a consciência moral aparece como vinda de fora, projetada e encarnada no outro.

Coelho dos Santos e Oliveira (2012) destacam que a não simbolização da função desempenhada pelo ideal do eu e, portanto, pelo pai, trata-se de um fato decisivo para a distinção entre neurose e psicose. Nesta última, o ideal do eu aparece regressivamente como outro hostil, que vigia e persegue, ao passo que na primeira, a formação do ideal aparece como condição para a repressão (Freud, 1914c/2006).

Tal problemática, a da função do ideal do eu na psicose, será abordada por Lacan através do conceito do significante Nome-do-pai e sua operação de foraclusão. O mecanismo da Verwerfung proposto por Freud será pensado como a rejeição deste significante especial que tem como função estabelecer a relação do sujeito com a linguagem e sem o qual não se opera a estruturação psíquica da realidade.

\section{Processo primário no âmbito das Representações de Palavras: limites do método psicanalítico}

Algumas particularidades da psicose foram tratadas por Freud em "O inconsciente" (1915/2006), tais como a ideia de que há, nessa modalidade clínica, uma tentativa de recuperação da relação com o mundo por meio do investimento na representação de palavra. O recalque, próprio à neurose, opera ao impedir que pensamentos ou sentimentos sejam traduzidos em palavras. A amnésia típica dos sintomas histéricos testemunha bem isso. Freud se apropria do termo 'representação', um termo clássico da filosofia e psicologia alemãs, usando-o de forma particular para tratar das representações inconscientes. O supracitado mecanismo do recalque visa separar no âmbito das representações a representação de palavra (Wortvorstellung) das 
representações de coisa (Sachvorstellung) e com isso, suprimir o afeto. Porém, o afeto ou a ideia continuam sendo investidos no inconsciente através da ligação com a representação de coisa (Sachvorstellung), como traços retranscritos na memória associados em um sistema. Deste modo, o afeto ligado às representações de coisa (Sachvorstellung) mantém-se inconsciente, por não estar ligado às representações de palavra (Wortvorstellung) as quais Ihe qualificariam e the forneceriam o estatuto da consciência (Freud, 1915/2006).

O presente texto apresenta uma revisão acerca do que Freud defendia como processo secundário. Até então, trazer à consciência os pensamentos inconscientes se definia pela capacidade de traduzir tais pensamentos ou sentimentos em palavras. $\mathrm{O}$ caso da psicose obriga a esta revisão dado que as regras do funcionamento inconsciente se efetuam no âmbito da palavra. No caso da psicose, a tradução em palavras não garante o domínio do processo secundário que passa a ser definido como a união, o encontro da representação de coisa (Sachvorstellung) com a representação de palavra (Wortvorstellung) propiciando uma estabilidade para o ego.

Já o mecanismo específico da psicose causaria uma radical tentativa de fuga por parte do ego, uma retirada de investimento psíquico não apenas das representações de palavra, como no caso das amnésias na neurose mas, também das representações de coisa. Por este motivo, a análise de um psicótico proporciona concepções que tornam o inconsciente menos enigmático e mais tangível.

Na psicose, após a defesa, a libido esforça-se por religar-se, no sentido de alcançar novamente os objetos, ligando-se às representações verbais pertencentes a eles (Freud, 1917a/ 2006). De acordo com Freud (1915/2006, p. 121), são tentativas que se dirigem para a recuperação do objeto perdido por meio de seu aspecto verbal, contentando-se com palavras em vez de coisas.

Freud observou que, na psicose, as palavras estão sujeitas aos processos psíquicos primários, passando por condensações e deslocamentos. Dessa forma, algumas ideias podem apropriar-se da intensidade das outras assim como podem transferir sua intensidade (Freud, 1915/2006 p. 118). Como consequência, o discurso destes pacientes apresenta-se com modificações e acentuada desorganização, expressando pensamentos os quais um neurótico só poderia revelar por meio do processo de análise (Freud, 1915/2006).

Como a defesa na psicose é mais enérgica (Freud, 1894/ 2006) e não separa o afeto de uma representação pela via da dissociação entre representação de palavra e representação de coisa como ocorre na neurose, não caberia ao seu tratamento a técnica de ligar novamente estes componentes psíquicos, separados pela ação do recalque. Por isso, é possível afirmar que o tratamento analítico idealizado por Freud, o qual estabelece a ligação entre representações de coisa e representação de palavra, leva em conta a censura típica da neurose. Nele, o objetivo é atenuá-la por meio da associação livre, de modo que seja possível vislumbrar os derivados inconscientes. Ou seja, o tratamento psicanalítico se baseia na influência do inconsciente a partir 
da direção do consciente, utilizando-se dos derivados do inconsciente, intermediários entre os dois sistemas, como meios de desvendar o caminho do recalque (Freud, 1915/2006), tal método, não obstante, torna-se inoperante nos casos de psicoses.

\section{A perda da realidade e a função do delírio}

O contato com a psicose e os fenômenos que dela decorrem, tais como as alucinações e os delírios, levou Freud (1900/2006, p. 151) a relacioná-la aos métodos primitivos de funcionamento do aparelho psíquico. Isso porque, desde cedo considerou como tendência primeira do organismo reviver uma experiência prazerosa de modo alucinatório. Assim sendo, a emergência de alucinações em psicóticos fez com que destacasse o restabelecimento de uma antiga modalidade de satisfação, uma vez que a alucinação é retratada, em sua obra, como uma via para realização do desejo.

Em sua elaboração teórica, delírios, alucinações e todos os fenômenos decorrentes do represamento libidinal já são tentativas de cura, de modo que, por meio destes recursos, o psicótico buscaria readquirir sua relação com as pessoas e o mundo, ainda que de maneira muitas vezes hostil, quando antes era afetuosa (Freud, 1911a/2006). Quanto à ocorrência de alucinações, sua explicação remete à ideia de um ego que se encontra desintegrado, comprometendo o teste de realidade que impediria o vetor regressivo da pulsão. (Freud, 1917/2006, p. 136-137).

Segundo Freud (1924b/2006), tanto a neurose quanto a psicose são rebeliões do id contra o mundo externo e as exigências da realidade. Ao estabelecer comparações entre as duas formas de doença, enfatizou que, em ambas, há uma perda de realidade, não sendo possível afirmar, portanto, que esta só se opere na psicose. A diferença residiria no fato de que, na neurose, num primeiro momento ocorre um sucesso da defesa e uma manutenção da relação com a realidade.

Para a teoria freudiana, a neurose resultaria de um conflito entre o Id e o mundo externo, onde o ego toma partido da realidade em detrimento das exigências da pulsão. Ela se caracteriza mais especificamente a partir de um fracasso da defesa, quando o Id impõe suas exigências diante da censura, causando mal estar, inibição, angústia ou o sintoma em si. A fuga da realidade se dá em um segundo tempo, o tempo do retorno do recalcado, apresentando-se de modo parcial e relativa ao que desperta relações com o motivo do recalque, a exemplo da fobia.

No caso da psicose, definida como um conflito entre o Id e o mundo externo em que o ego toma o partido do $I d$, Freud irá presumir que haveria, igualmente, dois tempos: um primeiro no qual uma ação arrasta o ego para longe da realidade, esvaziando a realidade de sentido e, um segundo, com um caráter de uma reparação da realidade, através do delírio e das alucinações.

Em uma psicose, a transformação da realidade é executada sobre os precipitados psíquicos de antigas relações com ela - isto é, sobre os traços de memória, as ideias e os julgamentos anteriormente derivados da realidade e através dos quais a 
realidade foi representada na mente. Essa relação, porém, jamais foi uma relação fechada; era continuadamente enriquecida e alterada por novas percepções. Assim, a psicose também depara com a tarefa de conseguir para si própria percepções de um tipo que corresponda à nova realidade, e isso muito radicalmente se efetua mediante a alucinação. (Freud, 1924b/2006, p. 108-109)

Nessa circunstância, o momento crucial do adoecimento na psicose é extremamente silencioso e diz respeito ao primeiro tempo. Segundo Freud (1924b/2006), a primeira etapa da psicose já se constitui como patológica por si mesma, visto que o abandono do interesse pelo mundo externo só pode conduzir à enfermidade. Neurose e psicose diferem, assim, muito mais na reação introdutória da doença do que na tentativa de reparação, porque na neurose podemos encontrar a produção de fantasias.

Freud (1924b/2006) salienta que a diferença inicial se expressa no desfecho final, dado que a neurose ignora a realidade e a psicose a repudia e tenta substituí-la. Entretanto, apesar da neurose levar mais em consideração a realidade do que a psicose, Freud chama a atenção para o fato de que o comportamento normal, sadio, se assemelha ao da psicose, ao tentar alterar a realidade inóspita. A diferença é que na psicose o sujeito se detém a efetuar mudanças internas enquanto que a normalidade seria a do sujeito conduzido à realidade do trabalho no mundo externo.

Ao acompanhar o percurso freudiano, é possível encontrar inúmeros trechos nos quais se expõe a dificuldade de tratar pacientes psicóticos. Neles, Freud afirma que seu método e técnicas não seriam apropriados nestes casos, além de indicar que uma modificação apropriada do método poderia ser capaz de superar tal contraindicação (Freud, 1905C/2006, p. 163). Jacques Lacan ocupou-se justamente desta questão em seu ensino como veremos adiante.

\section{A determinação simbólica e a desubstancialização do sujeito}

No período inicial de seu ensino, Lacan desenvolveu a tese de que é no campo da linguagem e na função da fala que se encontram as bases para a afirmação da descoberta freudiana: o inconsciente e a sexualidade (Lacan, 1953/1998). Visou a retomada dos fundamentos da experiência analítica que, a seu ver, foi desvirtuada por analistas pós-freudianos, notadamente os norte-americanos e, nesse sentido, mediante interlocuções com antropologia de Lévi-Strauss e a linguística de Jakobson e Saussure, Lacan aproximou a psicanálise do estruturalismo, articulando à ordem simbólica uma estrutura para o inconsciente. No contexto, avaliou que a proibição do incesto - Lei primordial de passagem da natureza à cultura, que tem por referência a relação de parentesco (Lévi-Strauss, 1940/1976) - fez valer interditos, estruturando as trocas e as relações sociais e, mais precisamente, o próprio sujeito como ser desnaturalizado, produtor de um modo distinto de relação com a realidade. A teoria do significante retranscreve sobre novas bases as considerações acerca da categoria de 'representação' usada por Freud, bem como promove uma 
releitura do complexo de Édipo e de Castração em função dos registros do simbólico, real e imaginário.

De sua perspectiva, portanto, o simbólico instaura a cultura e, por seu intermédio, fundase a estrutura da linguagem - que é determinante de tudo o que tem valor de existência para o ser humano (Lacan, 1954-1955/1985). Dessa maneira, o simbólico, compreendido igualmente como campo do Outro (Autre), oferece sentido às funções do sujeito que, a partir de um referencial contrário ao cogito cartesiano, é fundado como efeito e não como causa, uma vez que o campo alteritário da linguagem Ihe é anterior. E, em seu âmbito, revelam-se, segundo Alves (2012, p. 76), questões que aludem "à sua espécie, sua linhagem, sua cultura, sua família, o inserindo numa linha de ascendência e de descendência"; por conseguinte, a um lugar subjetivo a ser ocupado, no qual ele, sujeito, se reconhece e se faz reconhecer.

Apesar de Freud não o ter circunscrito, Lacan localizou a categoria de sujeito, pensado pela filosofia, nas entrelinhas de sua obra e, no transcurso de suas elaborações, esforçou-se para subtraí-lo de uma ênfase substancialista dando-lhe um estatuto específico que, levando à sua desubstancialização, permitiu a estruturação de um dos axiomas centrais do seu ensino: o de que o sujeito surge entre a articulação de significantes, sendo aquilo que um significante representa para outro significante (Lacan, 1957/1998).

Trata-se, desse modo, de um sujeito que, na clínica, surge, contingencialmente, nas equivocações da fala, onde o discurso do eu é atravessado pela incidência do sujeito do inconsciente. Lacan não equaciona o ser ao pensamento, tal como a filosofia de Descartes, e as formações do inconsciente demonstram que a existência não se reduz ao eu. Ao contrário de um caos desorganizado, o inconsciente tem leis próprias (Lacan, 1957-1958/1999) - uma vez que, no contexto da formulação da tese do inconsciente estruturado como linguagem, Lacan (1957/1998) subverteu o signo linguístico de Saussure, dando autonomia do significante em relação ao significado e problematizando a significação.

O que se extrai da impossibilidade de significação completa, dado que um significante não pode oferecer uma significação última, é que há uma hiância produzida na linguagem, em que o desejo vem fundar-se como metonímia da falta-a-ser. Quer dizer, a impossibilidade de uma inscrição total remete à castração, signo do drama edípico, como a via pela qual presentifica-se a incidência da falta-a-ser na constituição do sujeito pela linguagem (Lacan, 1957/1998).

\section{O Nome-do-Pai, a Metáfora Paterna e o Complexo de Édipo}

No seminário dedicado às psicoses, Lacan (1955-1956/1985) formalizou seu conceito de Nome-do-Pai, articulando-o ao conceito de uma Verwerfung primitiva que, tratando-se da rejeição de um significante primordial, refere-se à possibilidade de que "alguma coisa não seja simbolizada, que vai se manifestar no real" (Lacan, 1955-1956/1985, p. 98). A partir daí, considerado como um operador estrutural (Lacan, 1957-1958/1999) que, juntamente com o significante Falo constitui o 
sujeito do inconsciente na ordem simbólica, o Nome-do-Pai foi concebido como uma metáfora e, como tal, "um significante que substitui um outro significante" (Lacan, 1957-1958/1999, p. 180). Nessa perspectiva, é capaz de estabelecer a interdição simbólica através da operação da metáfora paterna (Lacan, 1957-1958/1999) substituindo o primeiro significante introduzido na simbolização: o significante materno - o do Desejo da Mãe, definido como o desejo do Outro com que nos deparamos na entrada no mundo simbólico.

Atuando, assim, como o agente que separa a criança e a mãe, Nome-do-Pai é, igualmente, apresentado por Lacan (1957-1958/1999, p. 152) como o "pai simbólico [...] que, no Outro como sede da lei, representa o Outro. É o significante que dá esteio à lei, que promulga a lei" (Lacan, 1957-1958/1999, p. 152). Ocupando um lugar de exceção, coloca-se como um ponto de basta no deslizamento incessante do significado sob o significante, constituindo uma rede de significantes ao seu redor e criando o campo das significações.

Como pivô dessa operação inaugural de substituição do desejo materno, possibilita que a criança renuncie à identificação primordial de ser o falo - o objeto imaginário com o qual a criança se identifica para satisfazer o desejo da mãe (Lacan, 1957-1958/1999) - para mobilizar seu próprio desejo para outros objetos substitutos a esse objeto perdido. Logo, o que se coloca em jogo é uma determinada relação ao saber, como articulação significante.

Ao abordar a questão da constituição do sujeito, Lacan (1957-1958/1999) o faz através dos três tempos lógicos do Édipo: no primeiro tempo a criança procura situar-se como objeto de amor para a mãe, identificando-se com o falo e se colocando na posição de ser ou não ser o falo para ela, e nesse sentido, cria uma unidade com a mãe que só será rompida após sua descoberta da castração materna; no segundo tempo, transmite-se a significação fálica quando o significante do desejo da mãe foi afetado pelo Nome-do-Pai. O pai é imaginário, um privador, barrando a mãe e a criança, na medida em que interdita a satisfação de seu impulso. $E$, no terceiro tempo, quando o pai se mostra como o detentor do falo, interferindo como autoridade, permite à criança a identificação com as insígnias do pai e a construção do Ideal do Eu e Superego. Trata-se, então, de um pai que, além de dizer não, diz também um sim: um pai doador que une à Lei um desejo. $\mathrm{E}$ o fundamental é que a mãe o constitua "como mediador daquilo que está para além dela e de seu capricho, ou seja, pura e simplesmente, a lei como tal. Trata-se do pai, portanto, como Nome-doPai" (Lacan, (1957-1958/1999, p. 197).

Desse modo, servindo-se das elaborações freudianas (Freud, 1914c/2006), que em sua leitura pautaram-se na perspectiva significante, Lacan assinala, com o declínio do Complexo de Édipo, a internalização do pai no sujeito como Ideal do eu. Uma identificação simbólica, constituinte do sujeito, pois que permite uma identificação à sua posição sexuada: "A metáfora paterna desempenha nisso um papel que é exatamente o que poderíamos esperar de uma metáfora - leva à instituição de alguma coisa que é da ordem do significante, que fica guardada de reserva, e cuja significação se desenvolverá mais tarde" (Lacan, 1957-1958/1999, p. 201). 
O Édipo remetendo, assim, a uma Lei de simbolização, possibilita um ponto de apaziguamento face ao enigma do desejo da mãe bem como o engendramento de significações fundamentais para o posicionamento da criança na partilha sexual.

Em suas formulações, Lacan (1957-1958/1998), retomou o termo Verwerfung, utilizado por Freud (1918 [1914] /2006) e postulou o conceito de foraclusão do significante do Nome-doPai, referindo-se à rejeição desse significante primordial que, no conjunto dos significantes, introduz a lei paterna na dialética edipiana:

É esse o Nome-do-Pai e, como vêem, ele é, no interior do Outro, um significante essencial, em torno do qual procurei centrá-los no que acontece na psicose - a saber, que o sujeito tem de suprir a falta desse significante que é o Nome-do-Pai. Tudo o que chamei de reação em cadeia, ou de debandada, que se produz na psicose, ordena-se em torno disso. (Lacan, 1957-1958/1999, p. 153)

Designando-o, por conseguinte, como o mecanismo na origem da estruturação psicótica estabeleceu uma clínica diferencial com a neurose, avaliando que essa é uma questão preliminar a ser considerada a todo tratamento possível da psicose - uma vez que na estrutura psicótica não há a colocação substitutiva do pai, como significante, no lugar da mãe e, em decorrência, o sujeito permanece identificado ao seu objeto.

Em decorrência da não inscrição do Nome-do-Pai como falta simbólica no Outro, isto é, da realidade da castração, a mãe aparece como completa, supondo que nada the falte. Coloca, portanto, o filho no lugar do falo, ou seja, em uma posição de objeto e, nesse sentido, deixa-o fora do gozo fálico - principal consequência da operação da metáfora paterna.

Lacan, ainda no contexto de suas discussões sobre o que concerne e constitui o sujeito em sua relação com a linguagem, no texto Resposta ao comentário de Jean Hyppolite sobre a Verneinung (1954/1998) bem como no seu seminário sobre as psicoses (LACAN, 1955-1956/1985), também admitiu que uma Bejahung - afirmação primordial - pode faltar. A Bejahung implica no reconhecimento de que algo existe, levando, em decorrência, ao surgimento de um campo de representação; tratando-se, portanto, de um tempo de nomeação, essencial para que se possa constituir o que é interno e o que é externo, dentro e fora. Assim, é uma condição prévia, para o ingresso do infans na ordem simbólica.

Dessa forma, a sua falta pode ser equacionada a uma recusa ao acesso ao mundo simbólico que, na compreensão de Lacan (1955-1956, 1985, p. 21) é a recusa de algo que o sujeito experimentou: "Pode acontecer que um sujeito recuse o acesso, ao seu mundo simbólico, de alguma coisa que, no entanto, ele experimentou e que não é outra coisa naquela circunstância senão a ameaça de castração". 
Assim, enquanto na neurose o saber recusado retorna e produz as significações nos sintomas neuróticos e em outras formações do inconsciente, em função do recalque decorrente da inscrição fálica no Édipo; na psicose, a falta do significante do Nome-do-Pai aponta uma recusa do sujeito para a ordem simbólica, face à ameaça da castração. Na psicose, não há recalque e, de acordo com Lacan (1955-1956/1985), o ponto de partida a ser considerado é o de que "o inconsciente está aí, presente na psicose. Os analistas o admitem com ou sem razão, e nós admitimos com eles que é em todos os casos um ponto de partida possível. O inconsciente está ali, mas isso não funciona" (Lacan, 1955-1956/1985, p. 167).

Nessa circunstância, a psicose evidencia a ruptura entre significante e significado sem o anteparo da metáfora paterna que fornece um tratamento para o campo da significação promovendo a inscrição da falta-a-ser, e o retorno do que não pôde ser simbolizado dá-se no real, conforme assinalado por Lacan (1955-1956/1985, p. 22): "o que é recusado na ordem simbólica ressurge no real". Posição essa que mantém o psicótico em uma significação endereçada a ele próprio e experimentada como uma imposição externa, precisamente onde se esperaria uma subjetivação. Nesse sentido, a foraclusão do significante do Nome-do-Pai, não permite a articulação da cadeia significante, comprometendo toda a estrutura da realidade compartilhada. $\mathrm{E}$, ao contrário do que ocorre na neurose - em que o afastamento de uma representação incompatível à consciência rompe, parcial ou completamente, com os fragmentos da realidade a qual ela se vincula - na psicose é "[...] a própria realidade que é em primeiro lugar provida de um buraco, que o mundo fantástico virá em seguida cumular" (Lacan, 1955-1956/1985, p. 57).

\section{A linguagem na psicose}

$\mathrm{Na}$ medida em que as psicoses expõem o funcionamento significante sem o ponto de ancoragem que o Nome-do-Pai possibilita, os efeitos da linguagem sobre o sujeito são evidenciados. E, para Lacan (1955-1956/1985, p. 167), "a promoção, a valorização na psicose dos fenômenos de linguagem é para nós o mais fecundo dos ensinamentos".

Sua tese é a de que o psicótico está na linguagem, mas, se na neurose, o sujeito habita a linguagem, na psicose, o sujeito é, por ela, habitado. Ou seja, o psicótico, enquanto mártir do inconsciente, fixa-se em uma posição que o deixa sem condições de restaurar o sentido do que testemunha, e de partilhá-lo no diálogo com o outro (Lacan, 1955-1956/1985). Tal contexto, em que uma significação não remete à outra, traduz o fenômeno psicótico, permitindo evidenciar a propriedade de o significante ser, em si mesmo, desprovido de significação, bem como a maneira como o sujeito psicótico encontra-se confrontado com rupturas de seu mundo e das significações que o sustentam na existência.

Lacan buscou elucidar, assim, a dialética imaginária e a relação especular do psicótico com o Outro, ao deparar-se com fenômenos próprios à estrutura do significante, pois, em função da 
foraclusão do Nome-do-Pai, as psicoses revelam o funcionamento significante sem esse ponto de basta.

Os fenômenos elementares, elevados por Lacan a fatos de linguagem específicos das psicoses, atestam que, o que é abolido da inscrição simbólica, retorna diretamente do real, como uma frase interrompida ou um neologismo e especialmente a alucinação - sua forma mais característica, entretanto, sem que o psicótico reconheça, no contexto, as alucinações ou ideias delirantes como suas produções. Ainda que a certeza seja a de que tudo isso lhe diga respeito. Desse modo, o que vem é de fora, do Outro e do semelhante.

Em seu texto "De uma questão preliminar a todo tratamento possível da psicose" (Lacan, 1957-1958/1998), uma distinção entre (a) fenômenos de código e (b) fenômenos de mensagem é estabelecida, considerando "o simples texto das alucinações". Dessa maneira, elucida que os fenômenos de código pertencem, por exemplo, às vozes que se servem da Grundsprache, traduzida por Schreber como língua fundamental. Ele a descreve como "um alemão um tanto arcaico, mas ainda rigoroso, que se caracteriza principalmente por uma grande riqueza de eufemismos" (Lacan, 1957-1958/1998, p. 544).

Conforme Lacan (1957-1958/1998), há também, nesse contexto, uma parte dos fenômenos que pode ser especificada por neologismos - das novas palavras compostas, ou em uma composição conforme às regras da língua do paciente, e também por seu emprego. Tratandose de algo próximo das mensagens denominadas de autônomas, segundo os linguistas - na medida em que é o próprio significante que é o objeto de comunicação, e não o seu significado. Entretanto, para Lacan, ainda trata-se de um efeito significante, que adquire um peso em proporção ao vazio enigmático que a significação revela.

Em relação aos fenômenos de mensagem, Lacan refere-se às mensagens interrompidas: "pela qual se sustenta entre o sujeito e seu interlocutor divino uma relação à qual elas dão a forma de um challenge ou de uma prova de resistência" (Lacan, 1957-1958/1998, p. 546). Frase que, dando igualmente a indicação da predominância da função do significante nas duas ordens dos fenômenos, se interrompe no ponto onde termina o grupo de palavras denominadas de termosíndice; que no código indicam a posição do sujeito a partir da própria mensagem e nas quais a parte propriamente léxica fica elidida.

Nesse sentido, a apresentação de um modo indireto, alusivo, de falar do sujeito é também uma das características do discurso psicótico. No contexto, as mensagens interrompidas de Schreber podem ser tomadas como exemplo, mostrando-se como distúrbios de conexão, em que a frase é cortada exatamente no ponto em que surgiria a significação. Assim, utilizando uma língua que Ihe é particular, desprovido de balizas simbólicas, Ele ouve: "Nisto eu quero..." e sente-se coagido a completar com "... pensar primeiro" ou "Agora eu vou me...", que refere-se a "...renderme ao fato de que sou burro". 


\section{Para concluir}

Algumas possibilidades atuais de tratamento puderam emergir a partir das contribuições freudianas. Seus estudos abriram portas para teóricos que se dedicaram a tratar da questão da psicose. Além disso, quando o delírio passa a ser considerado cura, altera-se a forma de olhar para o que seria então a enfermidade.

O caminho da criação através do delírio como tratamento tem sido considerado atualmente, os dispositivos de saúde mental visam possibilitar este lugar de construção de possibilidades, como se mediassem o retorno do fragmento da realidade rejeitada a fim de positivar o encontro do psicótico com esta realidade e a abertura na vida psíquica que ela pode causar.

Já no final de sua obra, em uma das "Novas conferências introdutórias" (Freud, 1933[1932]/2006), em meio a suas explicações e orientações, Freud novamente refere-se a uma radical inacessibilidade das psicoses. Porém, em "Construções em análise" (Freud, 1937/2006) chama atenção para o fragmento de verdade histórica presente nos delírios. Desta forma, propõe um caminho: o abandono do esforço de convencer o paciente psicótico de seus erros de percepção em detrimento de um reconhecimento de seu núcleo de verdade. O trabalho consistiria então em libertar o fragmento de realidade histórica de suas deformações a fim de reconduzi-lo as fontes infantis a que pertence (Freud, 1937/2006, p. 172-173).

É possível afirmar que Freud, no final de sua obra, deixa pistas acerca do que é possível realizar no tratamento de um psicótico. Este, não contará com o analista para reconstruir sua história esquecida, tampouco dará notícias de seu material inconsciente por meio de uma relação transferencial, mas poderá expor os métodos os quais utilizou para substituir o fragmento da realidade que outrora rejeitou.

Em 1924, Freud diz que "a elucidação dos diversos mecanismos que, nas psicoses, são projetados para afastar o indivíduo da realidade e para reconstruir essa última, constitui uma tarefa para o estudo psiquiátrico especializado, ainda não empreendida" (1924/2006, p. 2). Vimos como Lacan ao aplicar o paradigma linguístico ajuda a desvendar algumas razões para o impasse da psicose em relação à realidade uma vez que é foracluído o significante que permite a simbolização do ser do sujeito, mesmo que desubstancializado.

Chama-nos atenção as razões pelas quais é necessário o diagnóstico diferencial entre neurose e psicose: em Freud para garantir o sucesso do tratamento restringindo $\mathrm{e}$ desaconselhando seu uso nos casos de psicose; em Lacan essa diferenciação visa reposicionar a escuta do psicanalista, adequar desta forma o método à estrutura. 


\section{Referências Bibliográficas}

Alves, V. L. da S. (2012). O pequeno e o grande outro: conceitos de Lacan a partir de Hegel. Rio de Janeiro: Multifoco.

Coelho dos Santos, T. \& Oliveira, F. L. G. (2012, março). Teoria e clínica psicanalítica da psicose em Freud e Lacan. Psicologia em Estudo. 171), 73-82. doi: https://dx.doi.org/10.1590/S141373722012000100009 .

Freud, S. (2006). Sobre o mecanismo psíquico dos fenômenos histéricos: comunicação preliminar. In J. Salomão (Trad.) Edição standard brasileira das obras psicológicas completas de Sigmund Freud (vol. 2). Rio de Janeiro: Imago (Trabalho original publicado em 1893).

Freud, S. (2006). Neuropsicoses de defesa. In J. Salomão (Trad.) Edição standard brasileira das obras psicológicas completas de Sigmund Freud (vol. 3). Rio de Janeiro: Imago (Trabalho original publicado em 1894).

Freud, S. (2006). Rascunho H, paranóia. In J. Salomão (Trad.) Edição standard brasileira das obras psicológicas completas de Sigmund Freud (vol. 1). Rio de Janeiro: Imago (Trabalho original publicado em 1895).

Freud, S. (2006). Projeto para uma psicologia científica. In J. Salomão (Trad.) Edição standard brasileira das obras psicológicas completas de Sigmund Freud (vol. 1). Rio de Janeiro: Imago (Trabalho original publicado em 1950[1895]).

Freud, S. (2006). Projeto para uma psicologia científica. In J. Salomão (Trad.) Edição standard brasileira das obras psicológicas completas de Sigmund Freud (vol. 1). Rio de Janeiro: Imago (Trabalho original publicado em 1897).

Freud, S. (2006). A interpretação dos sonhos. In J. Salomão (Trad.) Edição standard brasileira das obras psicológicas completas de Sigmund Freud (vol. 5). Rio de Janeiro: Imago (Trabalho original publicado em 1900).

Freud, S. (2006). Três ensaios sobre a teoria da sexualidade. In J. Salomão (Trad.) Edição standard brasileira das obras psicológicas completas de Sigmund Freud (vol. 7). Rio de Janeiro: Imago (Trabalho original publicado em 1905a).

Freud, S. (2006). Sobre a psicoterapia. In J. Salomão (Trad.) Edição standard brasileira das obras psicológicas completas de Sigmund Freud (vol. 7). Rio de Janeiro: Imago (Trabalho original publicado em 1905b).

Freud, S. (2006). Notas psicanalíticas sobre um relato autobiográfico de um caso de paranoia (dementia paranoides). In J. Salomão (Trad.) Edição standard brasileira das obras psicológicas completas de Sigmund Freud (vol. 12). Rio de Janeiro: Imago (Trabalho original publicado em 1911a).

Freud, S. (2006). Formulações sobre os dois princípios de funcionamento mental. In J. Salomão (Trad.) Edição standard brasileira das obras psicológicas completas de Sigmund Freud (vol. 12). Rio de Janeiro: Imago (Trabalho original publicado em 1911b). 
Freud, S. (2006). A dinâmica da transferência. In J. Salomão (Trad.) Edição standard brasileira das obras psicológicas completas de Sigmund Freud (vol. 12). Rio de Janeiro: Imago (Trabalho original publicado em 1912a).

Freud, S. (2006). Recomendações aos médicos que exercem a psicanálise. In J. Salomão (Trad.) Edição standard brasileira das obras psicológicas completas de Sigmund Freud (vol. 12). Rio de Janeiro: Imago (Trabalho original publicado em 1912b).

Freud, S. (2006). Sobre o início do tratamento. In J. Salomão (Trad.) Edição standard brasileira das obras psicológicas completas de Sigmund Freud (vol. 12). Rio de Janeiro: Imago (Trabalho original publicado em 1913a).

Freud, S. (2006). Totem e tabu. In J. Salomão (Trad.) Edição standard brasileira das obras psicológicas completas de Sigmund Freud (vol. 13). Rio de Janeiro: Imago (Trabalho original publicado em 1913b).

Freud, S. (2006). O interesse científico da psicanálise. In J. Salomão (Trad.) Edição standard brasileira das obras psicológicas completas de Sigmund Freud (vol. 13). Rio de Janeiro: Imago (Trabalho original publicado em 1913c).

Freud, S. (2006). Recordar, repetir e elaborar. In J. Salomão (Trad.) Edição standard brasileira das obras psicológicas completas de Sigmund Freud (vol. 12). Rio de Janeiro: Imago (Trabalho original publicado em 1914a).

Freud, S. (2006). A história do movimento psicanalítico. In J. Salomão (Trad.) Edição standard brasileira das obras psicológicas completas de Sigmund Freud (vol. 14). Rio de Janeiro: Imago (Trabalho original publicado em 1914b).

Freud, S. (2006). Sobre o narcisismo: uma introdução. In J. Salomão (Trad.) Edição standard brasileira das obras psicológicas completas de Sigmund Freud (vol. 14). Rio de Janeiro: Imago (Trabalho original publicado em 1914c).

Freud, S. (2006). O inconsciente. In J. Salomão (Trad.) Edição standard brasileira das obras psicológicas completas de Sigmund Freud (vol. 14). Rio de Janeiro: Imago (Trabalho original publicado em 1915).

Freud, S. (2006). Suplemento metapsicológico à teoria dos sonhos. In J. Salomão (Trad.) Edição standard brasileira das obras psicológicas completas de Sigmund Freud (vol. 14). Rio de Janeiro: Imago (Trabalho original publicado em 1917a).

Freud, S. (2006). Conferência XXVII, transferência. In J. Salomão (Trad.) Edição standard brasileira das obras psicológicas completas de Sigmund Freud (vol. 16). Rio de Janeiro: Imago (Trabalho original publicado em 1917b).

Freud, S. (2006). História de uma neurose infantil. In J. Salomão (Trad.) Edição standard brasileira das obras psicológicas completas de Sigmund Freud (vol. 16). Rio de Janeiro: Imago (Trabalho original publicado em 1918[1914]). 
Freud, S. (2006). Neurose e psicose. In J. Salomão (Trad.) Edição standard brasileira das obras psicológicas completas de Sigmund Freud (vol. 16). Rio de Janeiro: Imago (Trabalho original publicado em 1924a).

Freud, S. (2006). A perda da realidade na neurose e na psicose. In J. Salomão (Trad.) Edição standard brasileira das obras psicológicas completas de Sigmund Freud (vol. 19). Rio de Janeiro: Imago (Trabalho original publicado em 1924b).

Freud, S. (2006). Novas conferências introdutórias sobre psicanálise. In J. Salomão (Trad.) Edição standard brasileira das obras psicológicas completas de Sigmund Freud (vol. 22). Rio de Janeiro: Imago (Trabalho original publicado em 1933[1932]).

Freud, S. (2006). Construções em análise. In J. Salomão (Trad.) Edição standard brasileira das obras psicológicas completas de Sigmund Freud (vol. 23). Rio de Janeiro: Imago (Trabalho original publicado em 1937).

Lacan, J. (1998). Função e campo da fala e da linguagem em psicanálise. Escritos (pp. 238-324). Rio de Janeiro: Jorge Zahar (Trabalho original proferido em 1953).

Lacan, J. (1998). Resposta ao comentário de Jean Hyppolite sobre a Verneinung de Freud. Escritos (pp. 383-401). Rio de Janeiro: Jorge Zahar (Trabalho original proferido em 1954).

Lacan, J. (1985). O seminário, livro 2: o eu na teoria de Freud e na técnica da psicanálise. Rio de Janeiro: Jorge Zahar (Trabalho original proferido em 1954-1955).

Lacan, J. (1985). O seminário, livro 3: as psicoses. Rio de Janeiro: Jorge Zahar (Trabalho original proferido em 1955-1956).

Lacan, J. (1998). De uma questão preliminar a todo tratamento possível na psicose. Escritos (pp. 537-590). Rio de Janeiro: Jorge Zahar (Trabalho original proferido em 1957-1958).

Lacan, J. (1998). A instância da letra no inconsciente ou a razão desde Freud. Escritos (pp. 496 533). Rio de Janeiro: Jorge Zahar (Trabalho original proferido em 1957).

Lacan, J. (1999). O seminário, livro 5: as formações do inconsciente. Rio de Janeiro: Jorge Zahar (Trabalho original proferido em 1957-1958).

Lacan, J. (1998). A significação do falo. Escritos (pp. 692-703). Rio de Janeiro: Jorge Zahar (Trabalho original proferido em 1958).

Lacan, J. (1998). Subversão do sujeito e dialética do desejo no inconsciente Freudiano. In J. Lacan, Escritos (pp. 807-842). Rio de Janeiro: Jorge Zahar (Trabalho original proferido em 1960).

Lacan, J. (2001). Abertura da seção clínica. Opção Lacaniana - Revista Brasileira Internacional de Psicanálise, (30), 6-9.

Lacan, J. (2005). O Simbólico, o imaginário e o real. Rio de Janeiro: Jorge Zahar.

Lévi-Strauss, C. (1976). Natureza e cultura. Estruturas elementares do parentesco (pp. 41-63).

Petrópolis: Vozes (Trabalho original publicado em 1947). 
Citacão/Citation: Martello, A., Andries de Castro, E. \& Rosa da Costa, R. (nov. 2017 a abr. 2018). 0 método analítico: do dispositivo freudiano à estrutura lacaniana. Revista aSEPHallus de Orientação Lacaniana, 13(25), 93-111. Disponível em www.isepol.com/asephallus. doi: 10.17852/1809-709x.2019v12n25p93-111.

Editor do artigo: Tania Coelho dos Santos.

Recebido/Received: 10/11/2016/11/10/2016.

Aceito/Accepted: 06/04/2017 / 04/06/2017.

Copyright: (c) 2018 Associação Núcleo Sephora de Pesquisa sobre o moderno e o contemporâneo. Este é um artigo de livre acesso, que permite uso irrestrito, distribuição e reprodução em qualquer meio, desde que o autor e a fonte sejam citados/This is an open-access article, which permites unrestricted use, distribution, and reproduction in any medium, provided the author and source are credited. 